\title{
Communication and Punishment in Voluntary Contribution Experiments
}

\author{
by Olivier Bochet, Talbot Page and Louis Putterman* \\ November 18, 2002, with Correction, November $2005^{* *}$
}

\begin{abstract}
We compare two devices previously found to increase contributions to public goods in laboratory experiments: communication, and punishment (allowing subjects to engage in costly reductions of one another's earnings after learning of their contribution decisions). We find that communication increases contributions more than punishment, and, taking into account the cost of punishment, only communication significantly increases subjects' earnings and thus efficiency.

We study three forms of communication to understand what elements of communication are essential to this result: exchanges of numerical messages, exchanges of verbal messages through a computer chat room, and face-to-face communication. Compared with a baseline of no communication and no punishment, we find that chat room communication increases cooperation and efficiency substantially, and when coupled with punishment opportunities nearly as much as face-to-face communication, even though the chat room environment does not communicate cues of facial expression, tone of voice, and body language. Face-toface communication is so effective that adding a punishment option to it does not significantly change the level of contributions or earnings. In contrast, communication limited to sending numerical messages has no net effect on contributions or efficiency.
\end{abstract}

JEL Classification: C91, H41, D23

Keywords: Public goods, collective action, communication, punishment, cheap talk.

\footnotetext{
* As of 2005, Bochet is at Maastricht University. Page and Putterman are at Brown University. The research reported here was supported by a Salomon Faculty Research Award from the Graduate School of Brown University, by a grant from the MacArthur Foundation Preferences Network, and by National Science Foundation grant SES-0001769. A preliminary analysis was presented at a meeting of the Economic Science Association, New York, June 18, 2000. We thank George Athanassacopoulos, Wouter Buitenhuis, Vicki Bogan, Mark Faktorovich, Chris Horn, Robert Letzler and John Mello for their supporting roles on our research team. Finally, we thank Norman Frohlich, Joe Oppenheimer, Jeannette Brosig and Axel Ockenfels for helpful responses to inquiries, and Ernst Fehr and Simon Gächter for numerous courtesies and kind encouragement. Please send comments to olivier.bochet@usa.net, Louis_Putterman@Brown.Edu or to Talbot_Page@Brown.Edu.

${ }^{* *}$ This version constitutes a correction of our original November 2002 working paper that alters only those figures, tables and statements affected by an initial error in handling data from one session of the CR treatment.
} 


\title{
Communication and Punishment in Voluntary Contribution Experiments
}

\author{
by Olivier Bochet, Talbot Page and Louis Putterman, Brown University
}

\section{Introduction}

In teams, firms and other groups, individuals are encouraged to undertake activities for the common good - law partners to do their share of rainmaking, professors their share of grant writing and advancing the name of the department, electric utilities to reduce their emissions of sulfur dioxide and mercury, and listeners of public radio to financially support it. Sometimes the encouragement is through communication and sometimes by more direct incentives like threatened reduction in earnings (fines and punishment). But when there are opportunities to free ride (or shirk), both economic theory and empirical observation suggest that free riding can erode cooperation far below its efficient levels.

Over the past 15 years experimental study of voluntary contribution mechanisms, which are versions of prisoners' dilemmas, has increased our understanding of the problem of cooperation on both theoretical and practical levels. The analysis has focused on two solution concepts, (iterated) dominance and Bayesian equilibria. As a test of the first concept, finitely repeated voluntary contribution mechanisms (VCMs) are designed to unravel from the end, with experimental subjects having iterated dominant strategies to free ride and contribute nothing. When subjects are given the opportunity to punish low contributing partners, exercise of this opportunity is made costly by design, so that iterated dominance predicts there will be no punishment either. When communication is allowed, by design there are no binding agreements so that communication reduces to "cheap talk" and is non-credible, according to standard game theory.

The experimental results have not confirmed the predictions of iterated dominance for payoff maximizers. Instead, experimentalists have found that communication increases cooperation, and punishment either increases it or prevents it from declining to the low levels of baseline treatments without communication or punishment.

These results appear consistent with Bayesian games, with common knowledge priors of heterogeneous types (see Kreps et al., 1982). In a Bayesian game where there 
are two types of preferences, one type where the utility is the monetary payoff and the other type where utility increases not only with increasing monetary payoff but also with increasing cooperation and reciprocity, it may take only a small prior probability of the second type to make it worthwhile for players of both types to invest in a reputation of reciprocity in the early periods of the game. ${ }^{1}$ In a realization of the Bayesian equilibrium of such a reputation game, there need not be any of the cooperative type players drawn for there to be incentives for payoff maximizing types of players to build reputations for reciprocity in the early periods.

Even though VCMs with 10 or more periods, 4 or more players, 2 or more player types, and complicated information structures have so far proved too difficult to solve for Bayesian equilibria, those studying behavior in such experiments have devoted increasing attention to signaling, reputation, and heterogeneous preferences associated with Bayesian games. Much of the recent work on VCMs has been to identify empirical regularities of signaling, reputation, cooperation and reciprocity dependent on variations in the VCM game form.

The main contribution of this paper is to find additional evidence supporting a Bayesian interpretation of cooperation. More specifically, in investigating three forms of communication, we found that communicating verbal messages through a computer chat room - which screens out identity, facial expression, tone of voice, and body language increased cooperation and efficiency substantially, when combined with punishment opportunities nearly as much as face-to-face communication, compared with a baseline of no communication and no punishment. In contrast, we found that "numerical cheap talk" nonbinding announcements of possible contribution levels that individuals could make and immediately revise in response to others' messages - had almost no net effect on total contributions or aggregate efficiency.

In comparing each of the three forms of communication with a treatment with punishment but no communication, we found that face-to-face communication and chat room communication increased cooperation and efficiency more than did punishment by itself.

In designing the experiment, we conjectured that opportunities to communicate and to punish might interact in ways such that each would enhance the effectiveness of the other. Communication might improve the efficiency of punishment by allowing subjects to

\footnotetext{
${ }^{1}$ See also McKelvey and Palfrey (1992).
} 
convey threats to punish low contributors at lower cost - i.e., without actually having to carry out the threats as often. If would-be punishers could credibly convey their intention to punish low contributions, high contributions might be elicited from the latter with less punishment and lower monetary costs of punishing and being punished.

We also conjectured that the opportunity to punish might add to the credibility of communication. By first threatening to punish low contributors and then carrying through by punishing low contributors in the early periods, the signal conveyed in the communication might be taken more seriously in the later periods. Moreover, verbal agreements for mutually high contributions made in face-to-face or chat room communication might be self-enforcing if subjects who made the agreement and stuck with it later saw others begin to free ride and, feeling betrayed, promptly exacted punishment.

We found that face-to-face communication by itself increased cooperation so much that the combined treatment of communication and punishment had only slightly higher levels of contribution than either chat room or face-to-face communication alone, and this difference was not statistically significant. Contributions were significantly higher when chat room communication was combined with punishment opportunities than when it was not. However, for each of the three forms of communication, earnings were about the same in a treatment without punishment as in a treatment with punishment, and the differences were not statistically different.

Moreover, while the opportunity to punish (without communication) clearly increased cooperation over baseline in agreement with the earlier literature, we found that the opportunity to punish did not increase efficiency in our experiment. Efficiency of punishment is limited in two ways. First, in our and other experiments including punishment, punishment is made costly to the punisher by design to reflect the costs of punishment in the real world. Second, to avoid leading subjects to act in a predetermined fashion, earnings reductions can be targeted at high and low contributors alike. As things turn out, most reductions are targeted at low contributors, but that doesn't prevent some high contributors from having their earnings reduced also. We found that about $20 \%$ of punishment dollars was targeted on subjects who contributed more than the average, and sometimes on those who contributed the maximum amount, in their group. Punishing the high contributors, what we call "perverse punishment," decreases their incentives to cooperate, as we found in a regression analysis. 
Indeed, an additional reason, not mentioned above, why combining communication with punishment might raise efficiency is that perverse punishment might be reduced by communication if it helps subjects come to a shared understanding of the nature of the problem facing them. ${ }^{2}$ This did not appear to be the case in our experiments, however.

In sum, we found that chat room communication was effective in increasing contributions and efficiency; when combined with punishment, it was as effective in increasing contributions and efficiency as face-to- face communication; numerical cheap talk had almost no net effect on contributions and efficiency; and face-to-face communication by itself increased contributions and efficiency about the same amount as did the combination of face-to-face communication and punishment.

These findings are related to the literature as follows. In an earlier study, Ostrom et al. (1992), found cooperators were sometimes punished in what the researchers called "blind revenge."3 Saijo and Nakajima (1995), also found evidence of punishing high contributors in a broader pattern they called "spite" (some subjects punish both high and low contributors to raise their own relative payoffs). Because the opportunity to reduce others' earnings is not always used in the experiment as a punishment for their actions, we adopt the more neutral term reduction in much of what follows, though we use the more familiar punishment interchangably with it in parts of our discussion.

The combined treatment of reduction and communication opportunities adds two degrees of freedom to the standard VCM with neither opportunity. Ostrom, Gardner and Walker (1992) found adding "a sword" to "a covenant," (adding a sanctioning option to pre-play face-to-face communication) the most effective way of approaching full efficiency in their common pool resource experiments, of the treatments they studied. Their experiment differs from ours and others in the VCM literature in having an interior optimum and no pre-announced ending period (it has a randomly selected last period).

Isaac and Walker (1988) and Sally's (1995) review of that paper and thirty-six other experiments found that non-binding face-to-face communication frequently led to contributions of entire endowments. Brosig, et al. (forthcoming) found that both face-to-

\footnotetext{
${ }^{2}$ Brosig et al. (forthcoming) note that verbal communication allows more astute subjects to help others in their groups to understand the structure of the public goods game. A clearer recognition that encouraging others to contribute is in their own interest might deter some perverse punishers.

3 "Blind revenge" refers to your attempt to get back at a person whom you suspect of having punished you. Such attempts are "blind" in the experiments of Ostrom et al., Fehr and Gächter (2000a) and the present paper, because subjects learn the total punishment assigned to them but not who has assigned it.
} 
face communication and audio-visual conferences among subjects seated in separated locations substantially increased contributions. They concluded that tone of voice, facial expression, and body language play a large part in accounting for communication's effects. This conclusion differs from our finding that verbal communication without visual cues can be as effective as face-to- face communication with visual cues, but our experimental set up differs somewhat from theirs, as discussed in Section 3.

Fehr and Gächter (2000a) found that introducing a costly opportunity to punish tended to increase average contribution levels monotonically, even when subjects were re-matched in each period with other groups of subjects, and even in the last period. Similar experiments, including Carpenter (2000), Sefton, Shupp and Walker (2002), and Page, Putterman and Unel (2002), found that while contributions don't always increase with repetition, the trend of decay was substantially mitigated.

Fehr and Gächter (2000a) interpreted the effectiveness of the punishment option as permitting subjects with a preference towards cooperation to punish free riders without reducing their own contributions, thus giving a clearer signal of their intentions than would the withdrawal of contributions, which is the only available punishment in the baseline VCM without communication or directly targeted punishment. Fehr and Gächter (2000a, 2000b) suggested that experimental subjects may include a certain fraction of "reciprocator" types in addition to the more standard payoff-maximizing types. The reciprocator types repay kindness with kindness and unkindness with punishment. A related notion is that of "assurance game preferences," which, following Sen (1967), transform prisoners' dilemma material payoffs into the utility payoffs such that when other agents cooperate, the agent in question is better off also cooperating. See Guttman (2000).

The effectiveness of communication in our own and other experiments suggests that not all subjects have pay-off maximization as their only goal, and that many attach positive probabilities to their fellow-subjects having non-payoff-maximizing preferences and/or entertaining the possibility of such preferences in others. High contributions and punishments in the final period of play suggest the presence of actual reciprocators (Andreoni and Miller, 1993, Falk et al., 2001; Page et al., 2002). These experimental results appear to be consistent with a Bayesian interpretation of VCMs.

The paper proceeds as follows. Section 2 specifies our experimental design. Section 3 presents experimental results and analysis. Section 4 provides discussion and 
concludes the paper.

\section{Experimental Design}

We conducted 22 experimental sessions of eight treatments. As shown in the left column of Figure 1, VCM experiments without reduction opportunities but including three different kinds of communication and a no-communication baseline constitute the first four treatments; as the right column shows, a second treatment corresponding to each of these four but adding reduction opportunities constitute the other four. In each session, sixteen inexperienced subjects, drawn from the general undergraduate population at Brown University, played a ten round repeated VCM game in groups of four. ${ }^{4}$ Except in the faceto-face (FF) treatment, subjects interacted only via computer terminals, and they could not tell which other subjects were in their group. ${ }^{5}$

Table 1: Design of the Eight Experimental Treatments

\begin{tabular}{|c|c|c|}
\hline & Without Reduction & With Reduction \\
\hline Baseline & $\begin{array}{c}\text { B } \\
\text { 3 Sessions } \\
4 \text { groups of } 4 \text { each Session }\end{array}$ & $\begin{array}{c}\mathbf{R} \\
\text { 3 Sessions } \\
4 \text { groups of } 4 \text { each Session }\end{array}$ \\
\hline Face to Face & $\begin{array}{c}\text { FF } \\
\text { 2 Sessions } \\
4 \text { groups of } 4 \text { each Session }\end{array}$ & $\begin{array}{c}\text { FFwR } \\
2 \text { Sessions } \\
4 \text { groups of } 4 \text { each Session }\end{array}$ \\
\hline Chat Room & $\begin{array}{c}\text { CR } \\
\text { 3 Sessions } \\
4 \text { groups of } 4 \text { each Session }\end{array}$ & $\begin{array}{c}\text { CRwR } \\
\text { 3 Sessions } \\
4 \text { groups of } 4 \text { each Session }\end{array}$ \\
\hline Numerical Cheap Talk & $\begin{array}{c}\text { NCT } \\
3 \text { Sessions } \\
4 \text { groups of } 4,2 \text { Sessions } \\
3 \text { groups of } 4,1 \text { Session }\end{array}$ & $\begin{array}{c}\text { NCTwR } \\
3 \text { Sessions } \\
4 \text { groups of 4, 2 Sessions } \\
3 \text { groups of 4, 1 Session }\end{array}$ \\
\hline
\end{tabular}

At the beginning of each decision period, each subject was provided

\footnotetext{
${ }^{4}$ Exceptions are two sessions with only 12 subjects each-see below.

5 Subjects sat at desks in a computer lab seating about 22 and were unable to communicate during the experiment and thus unaware of who they were grouped with. They were recruited mainly through the distribution of flyers to the campus mailboxes of the university's entire undergraduate population, with the experiments being identified as being conducted by researchers in the Economics Department. A brief postexperiment debriefing questionnaire shows that $16.1 \%$ of the subjects were economics concentrators, a little more than the approximately $10 \%$ of all undergraduates at Brown who were in that concentration at the time. $50.4 \%$ of subjects had taken one or more economics courses, with the average number of economics courses taken being 1.3. Subjects were broadly drawn from all classes, from freshman to senior. 52.6\% were females.
} 
(electronically) with ten experimental dollars and was asked to allocate it, in integer amounts, between a personal and a group account. Money placed in the personal account accrued to the individual subject and money placed in the group account was divided equally among all subjects in the group, with each receiving 0.4 times the total in the account. Thus, the earnings of a subject, $i$, in a given round of treatments without reductions, are

$$
\left(10-C_{i}\right)+(0.4) \Sigma \text { all j } C_{j}
$$

where $C_{i}$ (C for "contribute") is what $i$ assigns to the group account, and the summation is taken over all members of $i$ 's group. After each group member makes his or her contribution decision, each learns of the decisions of the others and of his or her own earnings. ${ }^{6}$ At the end of the experiment, the sum of the ten rounds of earnings were converted into real dollars at the rate of $\$ 0.13$ per experimental dollar, and each subject was paid a \$5 participation fee. Experiments lasted from one to one-and-three-quarter hours, and real earnings including the participation fee averaged around $\$ 25$.

\section{Reduction treatments}

In the treatments with reduction option, the assignment or contribution stage of each period was followed by a reduction stage. At the beginning of this stage, subjects learned the assignments to the group account of each other subject in their group. Individuals' identities were protected because assignments were displayed to other group members under labels "B," "C" and "D" only, and these labels changed randomly from one period to the next. ${ }^{7}$ A subject could then reduce the earnings of another subject at a 25 cent charge per one dollar of earnings reduction. ${ }^{8}$ Each subject then learned her earnings

\footnotetext{
${ }^{6}$ In many VCM experiments, only the group total is made known. We showed individual assignments in our baseline treatment to minimize differences from our treatments with reductions, where (as in Fehr and Gächter 2000a and the other experiments cited) subjects determine reductions of one another's earnings after learning of their individual assignments

${ }^{7}$ The same reshuffling of identifying letters from one round to the next is practiced in all eight treatments. This was done, following Fehr and Gächter (2000a), so that a subject could "punish" another group member for their behavior in the present period, only, thus ruling out vendettas (but not "blind revenge"- see above). ${ }^{8}$ Reductions could be imposed only in whole numbers of experimental dollars, so costs were in increments of 25 experimental cents. Some reduction number had to be typed in a reduction box for each group member, but this could be zero. There were two budget rules: (a) that one could not spend more on penalizing one's fellow group members in any round than one had earned in the assignment stage of that round, and (b) that one could not spend more on penalizing any given group member than would have brought that individual's earnings to zero for that round, ignoring that individual's own expenditures on reductions and the amount by
} 
for the period, which are equal to her earnings from the assignment stage minus her charges for reductions minus the amount by which her earnings have been reduced by other subjects. If this yielded a negative number, earnings for the period were set to zero. ${ }^{9}$

Thus earnings of subject $i$ are, for a period:

$$
\left(10-C_{i}\right)+(0.4) \sum_{j} C_{j}-(.25) \sum_{j} R_{i j}-\sum_{j} R_{j i}
$$

where $R_{i j}$ is the number of dollars by which $i$ reduces $j$ 's income. There were three sessions of the $\mathbf{R}$ treatment (i.e., with reductions but without communication), (see Table 1).

\section{Face-to -face communication treatments}

The communication stage of our FF (face-to-face) treatment resembles that in Isaac and Walker (1988) and Ostrom, Walker and Gardner (1992). Here, anonymity regarding group composition is lost, and the only restrictions are that threats and promises of sidepayments are ruled out. We ran two FF sessions of our VCM experiment without reduction option, and two FF sessions of the experiment with that option, dubbed FFwR (see Table 1). These sessions were identical to their no-communication counterparts $\mathbf{B}$ (baseline) and $\mathbf{R}$ (reductions only), described above, except that after the instruction period and before the ten decision periods, we informed the subjects which randomly formed groups they had been assigned to and invited each to talk to the other three members of his or her group for five minutes. The conversations took place in the four corners of the experiment room within earshot of the experimenters (to ensure the ground rules of no threats or offers of side payments), and the subjects then returned to their seats and

which that person is reduced by other group members. The first rule imposed a budget constraint, while the second rule protected participants from some wastage of their resources on over-penalizing others, but not from all such wastage, since "joint overkill" by the combined actions of several group members is still possible. We did not prevent such "joint overkill" because doing so would have allowed subjects to infer the choices that others made in the reduction stage, which might have exacerbated what in theory could already be a strong tendency to "free-ride" on punishing.

${ }^{9}$ Our baseline and punishment treatments differ from those in Fehr and Gächter in two respects. First, their subjects participated in both a baseline and a reduction treatment in the same session, with the baseline treatment sometimes coming before and sometimes after the treatment with reductions. By contrast, our basic design involves only one of these treatments per group, partly because, with seven rather than only two treatments of interest, there are too many possible sequences of treatments to be handled economically. Second, they specify the cost of reducing others' earnings in absolute cost per $10 \%$ reduction of the target subject's earnings for a period, with increasing marginal cost of these share reductions. With our reduction cost formula, it is easier to understand the cost of reducing the target group member by a given absolute amount, and the average and marginal costs of reductions are identical and constant. The approach is adopted in some later experiments by Fehr and Gächter as well; see Fehr and Gächter (2002). 
proceeded with the ten round experiment without further communication. Although each now knew which of the other subjects in the room had been assigned to his or her group, it was not possible for him (her) to track the decisions of specific individuals, since subjects did not know in advance what letters would be used for reporting one another's actions, and these letters were randomly assigned each period.

\section{Chat room treatments}

The chat room (CR) treatments offered a compromise between the more limited communication possibilities of the numerical cheap talk (NCT) treatment and the more open-ended possibilities of FF. Group members were brought together in an on-line chat room before the first, fourth, and seventh of the ten decision periods. In the chat room, they could discuss anything, subject to the no-threat and no-side-payments rules, and also to the injunctions that they not reveal to one another their identities or use obscene language. To ensure that these restrictions on communication were adhered to, each group's message flow was monitored by a member of the experiment team who was seated at one of the room's terminals and who had to approve each message before it was shown to the group (with a subject receiving a standard message from the monitor in the event that one of her messages was rejected). ${ }^{10}$ A successfully sent message was seen by all members of the subject's own group, but not those in other groups, each of which had its own chat room. In chat room communication, some of the open-ended character of faceto-face communication is possible, but anonymity is preserved, and it is more difficult to signal emotional states due to the unavailability of vocal intonation, facial expression, and body language. We carried out three sessions of the CR treatment in our VCM without reduction option, and three sessions of a $\mathbf{C R w R}$ treatment with reduction option as well as chat (see Table 1).

Numerical cheap talk treatments

In the numerical cheap talk (NCT) treatments subjects, who remained anonymous to one another, could communicate through the computer possible numerical choices to which

\footnotetext{
10 The average lag time introduced by this message clearance process was less than 5 seconds.
} 
they were not committed. We conducted three sessions of our NCT treatment without reduction stages, and three sessions with those stages, dubbed NCTwR (see again Table $1) .{ }^{11}$

In the treatment with numerical cheap talk and no reductions (NCT), each period of play had two stages, the first being a communication stage in which group members entered, in a screen of the same design as that used for binding decisions, what the instructions called "possible assignments" to the group account, then all were free to overtype their entries as they liked until a fixed amount of time ran out. ${ }^{12}$ In the second stage, first-stage numerical entries disappeared, a new screen heading announced "Binding Decision Stage," and actual contribution decisions were entered.

In the NCTwR treatment, there were three stages of each period: communication, assignment (or contribution) to the group account, and reduction. As before, the communication stage began with each subject typing in a possible assignment to the group account, again using essentially the same screen design used for binding decisions. ${ }^{13}$ When the assignments were revealed, each had to type in a possible reduction of each other group member, which could be zero. For the remainder of the communication stage, each subject was free to overtype and revise her assignment or her reductions or both until the time fixed for the communication stage expired. As with the NCT treatment, the contribution stage then followed, with subjects entering their binding contribution amounts into a clean version of the decision screen. The last stage, that of reductions, was identical to that in the $\mathbf{R}$ treatment, with a "Binding Decision Stage" screen heading and clean boxes into which reduction amounts were entered. An illustration of the decision screen appears in the Appendix.

The number of times in which subjects could engage in communication varied from zero in the $\mathbf{B}$ and $\mathbf{R}$ treatments to one time (before period 1) in the FF and FFwR treatments to three times (before periods 1, 4 and 7) in the $\mathbf{C R}$ and $\mathbf{C R w R}$ treatments to ten times (before each period) in the NCT and NCTwR treatments. The difference in frequency of communication between FF and NCT treatments was partly due to the greater

\footnotetext{
${ }^{11}$ In one NCT session and one NCTwR session, low show-up rates made it necessary to reduce the subject pool to 12 students, so that only three groups of four could be formed.

${ }^{12}$ The time allowed for communication was longer in early periods and shorter later on, after subjects got used to the process. Most changes were concentrated early in the cheap talk stages, so that the time constraint — at first 90 seconds, eventually 40 seconds - never appeared to be a binding one.

${ }^{13}$ The screen for non-binding communication was distinguished, however, by its color (yellow instead of blue) and by a screen label ("You are Now in the Communication Stage").
} 
speed with which numerical messages could be exchanged in NCT versus the time it took to assemble the groups for face-to- face meetings in FF. But we also experimented with only one FF meeting due to the high efficiency this led to in other experiments, and we kept to this design when we too had very high efficiency results. Our expectations for the effectiveness of NCT were less sanguine, and when achieved efficiency was even lower than we anticipated, we kept to the ten communication rounds design. We choose three communication periods in the $\mathbf{C R}$ treatments both because of the lower time expenditure than in FF (since subjects remain at their seats in $\mathbf{C R}$ ) and because we conjectured that $\mathbf{C R}$ communication would be less effective than $\mathbf{F F}$ in raising contributions.

A version of the full instructions for the experiment with reduction option and numerical cheap talk is shown in Appendix A. The paragraph of instructions specific to the FF and FFwR treatments is shown in Appendix B, while instructions specific to the $\mathbf{C R}$ and $\mathbf{C R w R}$ treatments are shown in Appendix C.

\section{Results and Analysis}

Figures 1 and 2 summarize the experiment's results by graphing the trends in contributions and earnings by period in our eight treatments. Results $1-3$ below confirm and strengthen earlier results in the literature. Results $4-6$ constitute the main new results of the paper.

Result 1: Our baseline treatment (treatment $\boldsymbol{B}$, with neither reduction nor communication) replicated standard findings (Davis and Holt, 1993) that contributions begin at $50 \%$ or more of endowment, and decline with repetition. Contributions began at an average of $62.9 \%$ of endowments, and declined to $19.6 \%$ of endowments in the last period (see Figure 1 and Table 2). A regression of average contributions on period which excludes period 10 (to exclude the large end-game effect apparent in all treatments) shows a statistically significant negative coefficient on period, consistent with an overall declining trend. ${ }^{14}$

\footnotetext{
${ }^{14}$ We estimate the regression $C_{i t}=\mathrm{b}_{\mathrm{o}}+\mathrm{b}_{1}$ (period) $+\mathrm{e}_{\mathrm{it}}$, where $C_{i t}$ is subject $i$ 's assignment or contribution to the group project in period $t$, the b's are coefficients to be estimated, and $\mathrm{e}_{\mathrm{it}}$ is an error term. The estimate of $\mathrm{b}_{1}$ is .5257, which has a t-statistic of -8.688 . There are 432 observations, and the R-square of the regression is 0.1493 , with $\mathrm{F}(1,430)=75.48$, significant at the .001 level.
} 
Table 2. Average Contribution to Group Account by Period and Treatment

\begin{tabular}{|c|c|c|c|c|c|c|c|c|}
\hline & $\mathbf{B}$ & $\mathbf{R}$ & $\mathbf{F F}$ & FFwR & $\mathbf{C R}$ & $\mathbf{C R w R}$ & NCT & NCTwR \\
\hline Period & & & & & & & & \\
\hline 1 & 6.29 & 6.96 & 10 & 10 & 9.33 & 9.42 & 6.57 & 6.43 \\
\hline 2 & 7.02 & 7.12 & 10 & 9.97 & 8.69 & 9.15 & 6.18 & 6.68 \\
\hline 3 & 6.79 & 6.94 & 10 & 10 & 7.75 & 9.50 & 6.07 & 7.39 \\
\hline 4 & 5.65 & 6.77 & 10 & 9.69 & 9.42 & 9.71 & 4.84 & 6.18 \\
\hline 5 & 4.58 & 7.37 & 9.69 & 10 & 8.31 & 9.87 & 5.14 & 7.29 \\
\hline 6 & 4.81 & 7.15 & 10 & 9.53 & 6.92 & 9.79 & 4.82 & 6.61 \\
\hline 7 & 4.54 & 6.75 & 10 & 10 & 9.00 & 9.96 & 3.98 & 6.41 \\
\hline 8 & 3.56 & 7.12 & 9.69 & 9.75 & 8.96 & 10 & 3.91 & 6.89 \\
\hline 9 & 2.33 & 7.06 & 9.06 & 9.87 & 7.83 & 9.79 & 3.39 & 7.50 \\
\hline 10 & 1.94 & 6.10 & 7.81 & 8.94 & 5.21 & 8.75 & 1.95 & 5.84 \\
\hline & & & & & & & & \\
\hline Average & $\mathbf{4 . 7 5}$ & $\mathbf{6 . 9 3}$ & $\mathbf{9 . 6 2}$ & $\mathbf{9 . 7 7}$ & $\mathbf{8 . 1 4}$ & $\mathbf{9 . 5 9}$ & $\mathbf{4 . 6 8}$ & $\mathbf{6 . 7 2}$ \\
\hline
\end{tabular}

Result 2: Our VCM experiments with a reduction option but no communication (treatment $\boldsymbol{R}$ ) are consistent with others in finding (a) higher initial contributions, (b) no decline in contributions until the end of the experiment, and (c) the absence of an overall earnings gain. Contributions began at an average of $69.6 \%$ of endowments, and the average was slightly higher, at $70.9 \%$ of endowments, in periods $5-9$, with a drop to $61.0 \%$ in period 10 (compared to $19.6 \%$ in period 10 in treatment B). A regression of average contributions on period for periods 1 through 9 shows no significant trend, so that while a small end- game effect appeared in period 10, adding a reduction option eliminated the overall downward trend of contributions found in simple VCM experiments, as in Fehr and Gächter (2000a). ${ }^{15}$

Table 3 shows the $p$-values for Mann-Whitney tests comparing average contributions and average earnings between each of the 28 pairs of treatments in our experiment. ${ }^{16}$ For the comparisons of the $\mathbf{B}$ and $\mathbf{R}$ treatments, these tests show that average contributions over the 10 periods taken as a whole were significantly higher in the

\footnotetext{
${ }^{15}$ Again estimating the regression $\mathrm{C}_{\mathrm{it}}=\mathrm{b}_{\mathrm{o}}+\mathrm{b}_{1}$ (period) $+\mathrm{e}_{\mathrm{it}}$ for periods $1-9$, the estimate of $\mathrm{b}_{1}$ is .0069 , with $\mathrm{t}$ statistic 0.211 . There are 432 observations, and the R-square of the regression is 0.0000 , with $F(1,1294)=0.04$, statistically insignificant at any reasonable level. Unlike Fehr and Gachter, whose set-up differs in details mentioned in footnote 9 , above, we do not find a tendency for contributions to increase with repetition in our own VCM with reduction option treatment.

${ }^{16}$ All tests take group-level averages as observations, since each group's behavior is independent of the others in its treatment given that there are no information flows across groups, even in the same session. For the comparison of the $\mathbf{B}$ and the $\mathbf{R}$ treatments, for example, we have 12 observations for each treatment (for numbers of observations, refer to Table 1).
} 
treatment with reductions than in the baseline treatment.

As in Fehr and Gächter (2000a), there was a willingness to impose costly reductions on other subjects' earnings, with $83 \%$ of subjects imposing at least one reduction during their ten round session. Also as in that experiment, reductions were aimed mainly at low

\section{Table 3. $p$-values of Mann-Whitney Tests on Group}

Average Contribution and Group Average Earnings by Pair of Treatments

\begin{tabular}{|c|c|c|c|c|c|c|c|c|}
\hline & B & $\mathbf{R}$ & FF & FFwR & CR & CRwR & NCT & NCTwR \\
\hline B & -------- & $\begin{array}{c}0.002 \\
C(R)>C(B)\end{array}$ & $\begin{array}{c}0.001 \\
C(F F)>C(B)\end{array}$ & $\begin{array}{c}0.001 \\
C(\text { FFwR })>C(B)\end{array}$ & $\begin{array}{c}0.001 \\
C(C R)>C(B)\end{array}$ & $\begin{array}{c}0.001 \\
\text { C(CRwR) } \\
>C(B)\end{array}$ & 0.74 & 0.096 \\
\hline $\mathbf{R}$ & 0.0977 & ------ & $\begin{array}{c}0.001 \\
C(F F)>C(R)\end{array}$ & $\begin{array}{c}0.001 \\
C(\text { FFwR })>C(R)\end{array}$ & $\begin{array}{c}0.083 \\
C(C R)>C(R)\end{array}$ & $\begin{array}{c}0.001 \\
\text { C(CRwR) }>C(R \\
)\end{array}$ & $\begin{array}{c}0.016 \\
\mathrm{C}(\mathrm{R})>\mathrm{C}(\mathrm{NCT} \\
)\end{array}$ & 1 \\
\hline FF & $\begin{array}{l}0.001 \\
E(F F)>E(B)\end{array}$ & $\begin{array}{c}0.001 \\
E(F F)>E(R)\end{array}$ & ------ & 0.234 & $\begin{array}{c}0.065 \\
\mathrm{C}(\mathrm{FF})>\mathrm{C}(\mathrm{CR})\end{array}$ & 0.97 & $\begin{array}{c}0.001 \\
C(F F)>C(N C \\
T)\end{array}$ & $\begin{array}{c}0.01 \\
C(F F)>C(N C T w \\
R)\end{array}$ \\
\hline FFwR & $\begin{array}{c}0.001 \\
E(F F w R)>E( \\
B)\end{array}$ & $\begin{array}{c}0.001 \\
E(F F w R)> \\
E(R)\end{array}$ & 0.279 & --- & $\begin{array}{c}0.011 \\
C(F F w R) \\
>C(C R)\end{array}$ & 0.27 & $\begin{array}{c}0.001 \\
C(\text { FFwR })>C( \\
\text { NCT })\end{array}$ & $\begin{array}{c}0.01 \\
C(\text { FFwR) }>C \text { (NC } \\
\text { TwR) }\end{array}$ \\
\hline CR & $\begin{array}{c}0.001 \\
E(C R)>E(B)\end{array}$ & $\begin{array}{c}0.002 \\
E(C R)>E(R \\
)\end{array}$ & $\begin{array}{c}0.079 \\
E(F F)>E(C R)\end{array}$ & $\begin{array}{c}\mathbf{0 . 0 1 7} \\
E(F F w R)>E(C R)\end{array}$ & ----- & $\begin{array}{c}0.039 \\
C(C R w R)>C(C R)\end{array}$ & $\begin{array}{c}0.004 \\
\mathrm{C}(\mathrm{CR})>\mathrm{C}(\mathrm{NC} \\
\mathrm{T})\end{array}$ & 0.175 \\
\hline CRwR & $\begin{array}{c}0.001 \\
E(C R w R)>E( \\
B)\end{array}$ & $\begin{array}{c}0.001 \\
E(C R w R)> \\
E(R)\end{array}$ & 0.571 & 0.208 & 0.349 & $\begin{array}{l}---1--1-- \\
----\end{array}$ & $\begin{array}{c}0.001 \\
\text { C(CRwR })>C( \\
\text { NCT })\end{array}$ & $\begin{array}{c}0.001 \\
\mathrm{C}(\mathrm{CRwR})>\mathrm{C} \text { (NC } \\
\text { TwR) }\end{array}$ \\
\hline NCT & 0.74 & 0.786 & $\begin{array}{c}0.001 \\
E(F F)>E(N C \\
T)\end{array}$ & $\begin{array}{c}0.001 \\
E(F F w R)>E(N C \\
T)\end{array}$ & $\begin{array}{c}0.004 \\
E(C R)>E(N C \\
T)\end{array}$ & $\begin{array}{c}0.002 \\
E(C R w R)>E(N \\
C T)\end{array}$ & ---- & 0.065 \\
\hline $\begin{array}{l}\text { NCTw } \\
\mathrm{R}\end{array}$ & 0.525 & 0.786 & $\begin{array}{c}0.001 \\
E(F F)>E(N C \\
\text { TwR })\end{array}$ & $\begin{array}{c}0.001 \\
E(F F w R)>E(N C \\
\text { TwR })\end{array}$ & $\begin{array}{c}0.002 \\
E(C R)>E(N C \\
\text { TwR })\end{array}$ & $\begin{array}{c}0.001 \\
\text { E(CRwR)>E(N } \\
\text { CTwR) }\end{array}$ & 0.699 & --- - - - - \\
\hline
\end{tabular}

Note: numbers above the diagonal are $p$-values for two-tailed tests comparing average contributions by group in the two treatments in question; numbers below the diagonal are $p$-values for the corresponding tests comparing average earnings by group. Notations below bold entries indicate the ordering of significant differences; for example, $\mathbf{C}(\mathbf{R})>\mathbf{C}(\mathbf{B})$ means contributions in treatment $\mathbf{R}$ are significantly greater than contributions in treatment $\mathbf{B}$. $\mathbf{E}(\mathbf{F F})>\mathbf{E}(\mathbf{B})$ means that earnings are significantly higher in the $\mathbf{F F}$ treatment than in the $\mathbf{B}$ treatment.

contributors. ${ }^{17}$ Such a pattern of punishments and of responses to punishment therefore

\footnotetext{
${ }^{17} 93.8 \%$ have their own earnings reduced at least one time in the experiment. The association between the amount a subject $j$ contributed to the group account and the amount by which that subject's earnings were
} 
helps to explain why there were higher contributions in the $\mathbf{R}$ than in the $\mathbf{B}$ treatment. As in Fehr and Gächter, contributions were higher even in the first period of the $\mathbf{R}$ treatment than in the first period of the $\mathbf{B}$ treatment, suggesting that subjects anticipated that low contributors may be punished, even before they had seen evidence of it in the experiment. Finally, punishment was substantial in the last period. Total dollars of reductions were significantly higher in period 10 than their average in periods 5 to 9 , according to a MannWhitney test at the group level. This shows that some punishments were non-strategic (carried out to increase the future contributions of others). ${ }^{18}$

Table 4. Average Earnings by Period and Treatment

\begin{tabular}{|c|c|c|c|c|c|c|c|c|}
\hline & $\mathbf{B}$ & $\mathbf{R}$ & $\mathbf{F F}$ & FFwR & $\mathbf{C R}$ & $\mathbf{C R w R}$ & $\mathbf{N C T}$ & $\mathbf{N C T w R}$ \\
\hline Period & & & & & & & & \\
\hline 1 & 13.77 & 12.98 & 16 & 16 & 15.60 & 14.53 & 13.94 & 11.67 \\
\hline 2 & 14.21 & 12.58 & 16 & 15.98 & 15.21 & 14.50 & 13.71 & 12.59 \\
\hline 3 & 14.07 & 12.05 & 16 & 15.96 & 14.65 & 15.05 & 13.81 & 13.35 \\
\hline 4 & 13.39 & 12.39 & 16 & 15.50 & 15.65 & 15.15 & 12.90 & 12.57 \\
\hline 5 & 12.75 & 12.55 & 15.81 & 16 & 14.99 & 15.19 & 13.08 & 13.27 \\
\hline 6 & 12.89 & 12.93 & 16 & 15.33 & 14.15 & 15.11 & 12.89 & 12.35 \\
\hline 7 & 12.72 & 11.99 & 16 & 16 & 15.40 & 15.66 & 12.89 & 11.88 \\
\hline 8 & 12.14 & 12.92 & 15.81 & 15.69 & 15.37 & 15.33 & 12.57 & 12.45 \\
\hline 9 & 11.40 & 12.91 & 15.44 & 15.92 & 14.70 & 15.59 & 12.03 & 13.31 \\
\hline 10 & 11.16 & 11.89 & 14.69 & 15.01 & 13.12 & 13.22 & 11.17 & 11.40 \\
\hline & & & & & & & & $\mathbf{1 4}$ \\
\hline Average & $\mathbf{1 2 . 8 5}$ & $\mathbf{1 2 . 5 2}$ & $\mathbf{1 5 . 7 7}$ & $\mathbf{1 5 . 7 4}$ & $\mathbf{1 4 . 8 8}$ & $\mathbf{1 4 . 9 3}$ & $\mathbf{1 2 . 8 9}$ & $\mathbf{1 2 . 4 8}$ \\
\hline
\end{tabular}

reduced by others in his or her group is further illuminated by estimating a regression in which total dollars by which $j$ 's earnings were reduced in a given period is the dependent variable, and $j$ 's contribution minus the average contribution of the other three members of $j$ 's group in the same period is the only independent variable, apart from a constant. With 480 observations on 48 subjects in 10 periods, the coefficient on the relative contribution term is -0.351 and the $t$-statistic is -11.2 , significant at the .001 level. Furthermore, such reductions can be shown to lead to higher contributions. There are 184 observations of subjects contributing less than their group's maximum in one or another of periods 1 through 9. Taking the change in such a subject's contribution the following period as dependent variable and making the number of dollars by which that subject's earnings were reduced an independent variable in an OLS regression that also includes a constant, the estimated coefficient on the amount of reductions is 0.374 , significant at the .001 level. The adjusted R-squared of the regression is .129.

${ }^{18}$ In each of the twelve groups at least one subject contributed less than $\$ 10$ to the group account in the last period, and in eleven of these groups at least one subject's earnings were reduced in that period. Falk et al.(2001) conclude that most punishment is non-strategic. 
Discussion. The introduction of punishment effectively changed incentives to contribute to the group account, since high contributors tended to earn more than low contributors in the $\mathbf{R}$ treatment, while the reverse held for the $\mathbf{B}$ treatment. ${ }^{19}$ However, the costliness of punishing and being punished led to no net gain in average earnings from introducing the reduction option in our experiment (see Table 4). Not only were earnings reduced by the costs of punishing free riders, but also $22 \%$ of reduction events were aimed at subjects who contributed more than their group average in the period in question, including 18\% aimed at a period's maximum contributor (perverse punishment). The high contributors who were punished tended to reduce their contribution by $\$ 0.50$ in period $t+1$ for every $\$ 1$ by which their earnings were reduced by punishment in period $t^{20}$

We begin discussion of our communication results with treatment FF.

Result 3: A five-minute pre -play face-to -face communication period dramatically raised contributions to the group account in all periods relative to their corresponding levels in the $\boldsymbol{B}$ and $\boldsymbol{R}$ treatments. As shown by Figure 1 and Table 2, members of the eight groups in the FF treatment contributed their entire endowments in periods 1, 2, 3, 4, 6, and 7; contributed more than $90 \%$ of their endowments in periods 5,8 , and 9 ; and nearly $80 \%$ of their endowments in period 10. Average contributions in the FF treatment exceed those in both the $\mathbf{B}$ and the $\mathbf{R}$ treatments in every period and, comparing the $\mathbf{F F}$ and $\mathbf{B}$ treatments, in every group. As Table 3 shows, Mann-Whitney tests confirm that groups in the FF treatment contributed and earned significantly more than groups in treatment $\mathbf{B}$, and likewise, than groups in treatment $\mathbf{R} .^{21}$

Discussion: The impact of communication on subjects' decisions is inconsistent with predictions for an environment of common knowledge of payoff-maximizing

\footnotetext{
${ }^{19}$ In the $\mathbf{B}$ treatment, high contributors earned less, as shown by the fact that the ten subjects with the lowest total earnings contributed an average of 5.1 experimental dollars per period, whereas the ten highest earning subjects contributed an average of 3.9 per period. In the $\mathbf{R}$ treatment, in contrast, the ten highest earners had contributed more - an average of 7.8 experimental dollars - than the ten lowest - an average of 5.5.

${ }^{20}$ In a regression equation in which the change in a subject's contribution from period $t$ to period $t+1$ is the dependent variable, and the number of dollars of punishment received in period $t$ multiplied by a vector of dummy variables for the punished subject's position as highest, second highest, third highest, or lowest contributor in their group in period $t$, the coefficient on the highest contributor dummy variable interacted with punishment received is -0.5 , significant at the $1 \%$ level. Research in progress on perverse punishment. ${ }^{21}$ Again, Mann-Whitney test observations are average earnings and average contributions, respectively, over the course of the entire experiment at group level. This yields 8 observations each for the $\mathbf{F F}$ treatment, 12 observations for the $\mathbf{B}$ treatment.
} 
behavior, but consistent with a world in which subjects assign some probability that their counterparts believe them to have preferences for reciprocity and/or truth-telling. That twenty-five out of thirty-two subjects continued to contribute their full endowments to the group account even in period 10 strongly suggests that many subjects actually have such preferences. The minority of subjects who contribute their full endowments in earlier periods but zero in period 10 can be understood to have feigned reciprocity for strategic reasons. $^{22}$

Evidently, a face-to-face meeting allowed subjects to jointly assess the problem facing them and to enter agreements to address that problem in a cooperative manner. But is the same effect possible if subjects remain anonymous to one another, are unable to convey impressions by way of body language, facial expression and vocal intonation, and cannot reduce "social distance" to the same degree as in a face-to-face interaction? The next result addresses this question.

Result 4: Open-ended but anonymous verbal communication in an on-line chat room was more effective in eliciting contributions to the group account than were punishment opportunities, but not as effective as was face to -face communication. Like the $\mathbf{F F}$ treatment, contributions in the $\mathbf{C R}$ treatment were significantly higher than those in both the $\mathbf{B}$ and the $\mathbf{R}$ treatments, according to Mann-Whitney tests (Table 3). The average contribution in the $\mathbf{C R}$ treatment was $15 \%$ less than that in the $\mathbf{F F}$ treatment, and a 2-tailed Mann-Whitney test finds a significant difference in contribution levels across groups in the two treatments at the $10 \%$ level only (see Table 3 ).

Discussion: Our results showed a chat room to be a surprisingly effective means of reaching an agreement and engendering trust and commitment, a result which seems to augur well for the conduct of business and other communications on-line. However, the fact that the subject pool consisted entirely of students in a university of moderate size (about 5800 undergraduates) and that each was aware of the presence of the other 15 subjects in the room may also be important to bear in mind (as discussed in Section 4). ${ }^{23}$ A review of the

\footnotetext{
${ }^{22}$ Some switches to low contributions in period 10 may also be due to beliefs that others would not contribute. An agent with a conditional preference for reciprocity or cooperation is not expected to contribute when he believes that others will not contribute.

${ }^{23}$ Recall also that unlike the FF treatment, where groups meet only once prior to actual decisions, the $\mathbf{C R}$
} 
contents of subjects' messages shows that about a quarter of substantive messages are concerned with discussion of what the best strategy would be (e.g.: "If we all keep putting in \$10, we'll all earn \$25.”), with most of the remaining messages being statements of commitment to the common strategy (e.g.: "I'm with you, A."), and morale and teambuilding remarks (e.g.: “That was a breeze, let's stick with this!”). ${ }^{24}$

The next question to be addressed is whether the "sword" (i.e. threat) of reductions enhanced cooperation in the FFwR and CRwR treatments, as it did in the communication and sanctions experiments of Ostrom et al.

Result 5: The addition of a punishment option to face-to -face meetings or chat room communication did not significantly alter the high level of cooperation seen in the $\boldsymbol{F F}$ treatment, but contributions were higher in the $\boldsymbol{C R} \boldsymbol{w} \boldsymbol{R}$ than in the $\boldsymbol{C R}$ treatment. Overall, there are no statistically significant differences in earnings among the FF, FFwR, CR, and CRwR treatments, and no significant differences in contributions between the FF, FFwR and CRwR treatments, all of which had somewhat higher contributions than CR. (see Table 3). All four treatments with communication had significantly higher earnings and contributions than those in the $\mathbf{B}$ treatment and in the $\mathbf{R}$ treatment, according to the Mann-Whitney test results in Table 3.

Although the above four treatments show similarly high contribution levels in general, there appears to be a modest difference in the size of the end-game decline in contributions in the FF versus the FFwR treatments, and a larger difference in end-game

treatment features three on-line meetings per session, before periods 1, 4 and 7 . We noted previously that this design was adopted in anticipation of the possibility that CR communication might otherwise be less effective than that carried on face-to-face. Due to this treatment difference, we can't infer from our results that $\mathbf{C R}$ and $\mathbf{F F}$ communication would be equally effective were both to occur only once. However, the opposite conclusion, that $\mathbf{C R}$ communication would have been significantly less effective than FF had both occurred with equal frequency, also cannot be derived with certainty. A noteworthy feature of CR subject behaviors is that average contributions decline in the periods before the second and third chat interludes, then rise again in what might be partly "recontracting" effect, partly a restart effect of the kind seen in VCM experiments without communication (see above). It seems likely that at least some part of these declines is attributable to subjects taking advantage of the pending communication periods by inflicting short-term damage on their groups' cooperative equilibria that they would not have risked were no communication opportunity at hand. That is, subjects looking for opportunities to free-ride with low risk of long-term damage might have reasoned that the pending communication opportunity could be used to shore up faltering cooperation, thus undoing the damage of their pre-meditated 'hit-and-run' behavior. For example, one subject switched from contributing 10 to contributing 0 in the period before chat communication, then begged his team-mates to believe that this change had been an unintended typing error-a tempting strategy in our design, indeed! Remember also that subject identification letters were scrambled before each chat period, so that a 'hit-and-run' defector could choose to hide behind the veil of anonymity. In many of these cases, cooperation was indeed restored, the violators evidently being forgiven or at least their misdeeds being put behind group members for the sake of prospective mutual gains.

24 "Substantive messages" excludes ones unrelated to the experimental task, by which group members killed time and attempted to amuse one another. About a third of total messages fall into the latter category. 
declines between the $\mathbf{C R}$ and $\mathbf{C R w R}$ treatments, which suggests that the prospect of punishment deterred some subjects from defecting in the last period. Beginning in period 8, there is a growing difference in average contributions between the FFwR and the FF treatment, reaching an average difference of $\$ 1.23$ in period 10 (see Table 2). ${ }^{25}$ Turning to the CRwR and CR treatments, Table 2 shows that most of the difference in average contributions was due to the declines in contributions in the pre-chat periods, 3, 6, 9 and 10. It seems likely that this is attributable to the deterrent effect of punishment in the last periods before restarts ${ }^{26}$ and the last period of the experiment as a whole. While contributions did show a period 10 decline in the CRwR treatment, suggesting that some subjects doubted they would be punished, those who contributed in period 10 out of fear of punishment did so with good reason: in $80 \%$ of groups in which at least one subject contributed less than $\$ 10$ in period 10, at least one subject punished one or more low contributors, paralleling the finding for period 10 in Result 2.

Discussion: Perhaps surprisingly, the record of CRwR messages shows few subjects explicitly proposed using reductions as a method of enforcement. Members of some groups even seemed to see the reduction option as a trap set by the experimenters to help keep down their earnings. ${ }^{27}$ Nonetheless, the fact that reductions were indeed used as punishments, and the higher contributions that resulted from this, suggest that many if not all subjects recognized that reneging on their group's agreement might invite retaliation.

Given the effectiveness of anonymous communication in chat rooms, it might seem that numerical messages might be effective as well. Our final result concerns the two numerical cheap talk treatments.

Result 6: Unlike the treatments with open-ended communication in face-to -face meetings or chat rooms, the addition of numerical cheap talk (NCT) did not result in additional cooperation. As inspection of Figures 1 and 2 suggests, the overall trend and level of contributions and earnings in the NCT treatment was not significantly different from that in the parallel $\mathbf{B}$ treatment, and the same relationship holds between the

\footnotetext{
${ }^{25}$ The difference is not significant according to a Mann-Whitney test, since there were also some FFwR groups that exhibited substantial last period declines. Note that low contributors were indeed punished in that treatment: out of a total of eight reduction events, six were of subjects contributing less than their group average in the period in which their earnings were reduced.

${ }^{26}$ Periods 4 and 7 are "restarts" in the sense that the flow of the game was interrupted just before these periods with chat room communications.

${ }^{27}$ Distaste or suspicion of punishment appears also in the experiment discussed by Ertan, Page and Putterman (in progress) in which subjects were asked to vote on whether or not to allow it. Initially, $50 \%$ of groups voted against allowing any punishment. But eventually, $85 \%$ of groups chose to allow punishing low but not high contributors after seeing the successes of groups choosing that approach.
} 
NCTwR and its counterpart, the $\mathbf{R}$ treatment. The NCT treatment shows the same declining trend in contributions and earnings as does the $\mathbf{B}$ treatment, while the NCTwR treatment shows the same stability of contributions and earnings through period 9 as does the $\mathbf{R}$ treatment. ${ }^{28}$ Mann-Whitney tests, summarized in Table 3, do not find significant differences between average contributions and earnings in NCT and those in B, or average contributions and earnings in NCTwR from those in $\mathbf{R} .^{29}$ Like the $\mathbf{R}$ treatment, overall contributions in the NCTwR treatment were higher than those in the NCT and B treatments, because contributions were more sustained over time. However, also like the $\mathbf{R}$ treatment and unlike the FF, FFwR, CR, and CRwR treatments, earnings were lower in the NCTwR treatment than in the NCT and B treatments, although the difference is not statistically significant.

Discussion: Failure of the NCT treatments to affect contributions, overall, may be due both to difficulties in reaching agreements and creating a sense of trust and commitment without verbal communication, and to the low subjective cost of lying given the "possible choice" description of numerical entries in the experiment's instructions. The similarity of the average net outcomes of the NCT and NCTwR treatments to their counterpart treatments without communication, $\mathbf{B}$ and $\mathbf{R}$, is consistent with the expectations of standard economic theory that communication is simply "cheap talk" when there is common knowledge that subjects are payoff maximizers. But a closer inspection of NCT messages and behaviors shows that most subjects attempted to achieve coordination on high-contribution equilibria, using the threat of punishment to enforce this in the NCTwR treatment. Consistent with this, some groups achieved high levels of cooperation in the NCT and R/NCT treatments than in their counterparts, the $\mathbf{B}$ and $\mathbf{R}$ treatment. What accounts for the absence of an overall effect is the fact that in other groups, subjects attempted to use misleading NCT messages to generate opportunities to free ride. The

\footnotetext{
28 Again estimating the regression $\mathrm{C}_{\mathrm{it}}=\mathrm{b}_{\mathrm{o}}+\mathrm{b}_{1}$ (period) $+\mathrm{e}_{\mathrm{it}}$, the estimate of $\mathrm{b}_{1}$ for subjects in treatment NCT is -.3958 , with $t$ statistic -5.095 . There are 396 observations, R-squared is 0.0618 , and $\mathrm{F}(1,394)=25.95$, significant at the .001 level. For the R-NCT treatment, the estimate of $b_{1}$ is .0625 , with $t$ statistic 1.447 . In this case, there are also 396 observations, the R-squared of the equation is 0.0018 , and $\mathrm{F}(1,1186)=2.09$, which is not significant at any conventional level.

${ }^{29}$ The comparisons of NCT to B involve observations for 11 NCT groups and 12 baseline groups. The comparisons of NCTwR to $\mathbf{R}$ involve observations for 11 R-NCT groups and 12 R groups.
} 
latter NCT and NCTwR groups achieved even poorer outcomes than did low-end performers in the $\mathbf{B}$ and $\mathbf{R}$ treatments. ${ }^{30}$

\section{Discussion and Conclusions}

Our public goods experiments with three forms of communication and a nocommunication baseline reconfirmed the strong effect of face-to-face communication on cooperation, resulted in surprisingly comparable effects for sharing of typed messages in on-line chat rooms, and found that merely exchanging possible numerical decisions did not on average foster cooperation. We reconfirmed that offering subjects the opportunity to reduce one another's earnings after learning of their contributions elicits many costly punishments, primarily of low contributors, thereby delaying the onset of the decay that is typical with repetition. But, partly because up to $20 \%$ of punishments were "perversely" aimed at high contributors, reduction opportunities did not raise contributions by as much as did $\mathbf{F F}$ and $\mathbf{C R}$ communication, nor did they significantly increase earnings either alone or in combination with FF, CR, or NCT communication. What implications do these findings have for understanding how and why some forms of communication succeed in fostering cooperation, and how the propensity to punish free riding might be harnessed more efficiently?

The fact that many of our experimental subjects in treatments with face-to-face or chat room communication contributed their full endowments in the last period, even in the absence of punishment opportunities, suggests that utility and monetary pay-offs do not coincide for many individuals. Last period contribution without threat of punishment

\footnotetext{
${ }^{30}$ We explore the richness of NCT interactions in a companion paper (Bochet and Putterman, 2002). The findings include: (a) in the numerical announcements, announced reductions are significantly positively related to the difference between the targeted subject's announced contribution and their group's average announced contribution; (b) subjects who announced low contributions adjusted their announced contributions upwards when threatened with reductions, whereas subjects who announced high contributions adjusted their announced contributions downwards when threatened with reductions; (c) subjects who actually contributed less in a binding decision stage than their last announced contribution in the communication stage of the same period were significantly more likely to be punished by other group members in the binding reduction stage; (d) the more lying or misrepresentation of intentions occurred in a group during the early periods of play, the lower were contributions in later periods; and (e) average contributions varied more from group to group in treatments with NCT than in the corresponding treatment (B or R) without it.
} 
suggests altruism, reciprocity, or an expectation of disutility from reneging on an agreement. Disutility from reneging on an agreement may help to explain why $\mathbf{C R}$ and $\mathbf{F F}$ but not NCT succeeded in fostering cooperation.

The content of the CR messages suggests that professions of commitment were also important to our results. Suppose that some subjects get disutility from reneging on an explicit promise regarding an action of mutual interest, so that they will not break that promise unless the payoff is high. Suppose, further, that many subjects believe that other subjects have such preferences, and that they also believe it to be possible to assess the likelihood that specific others have such preferences by means of verbal and other cues (Frank, 1988; Brosig, 2002). Then communication may foster cooperation by allowing subjects to issue explicit professions of commitment and to convince one another that they will not renege on their commitments given the stakes involved. Sally (1995) found communication to have a statistically and economically stronger effect on cooperation than any other treatment variable. Moreover, the effect of communication was significantly enhanced by experimenter suggestions that subjects could make promises to one another, so much so that Sally inferred that "messages have no significance beyond their ability to convey promises." The failure of our NCT treatments and the success of our CR treatments seem to support Sally's conclusion that "the specific medium of language may be an essential factor in influencing behavior."

Frohlich and Oppenheimer (1998) compared an email communication treatment to FF and no-communication treatments in a VCM experiment. Both Frohlich and Oppenheimer's results and our own found less cooperation with electronic than with faceto-face communication, but much more cooperation with electronic communication than with no communication. The difference between FF and electronic communication results was larger in their experiment than in ours (the average contribution was $24 \%$ lower in their e-mail than in the face-to-face treatment, whereas contributions are $15 \%$ lower in our CR than our FF treatment). ${ }^{31}$ Possible explanations include the fact that Frohlich and Oppenheimer's subjects communicated by e-mail rather than in a chat room, which deprived the subjects of a running record of their communications. Subjects had to open each e-mail message and may have received more than one message at a time in their five

\footnotetext{
${ }^{31}$ The difference is greater still if we ignore one poorly performing, hence perhaps anomalous, CR group. Without that group, $\mathbf{C R}$ contributions aren't statistically different from $\mathbf{F F}$ contributions at any conventional level.
} 
person groups, so the use of e-mail could have caused different group members to perceive the flow of group communications differently from one another. ${ }^{32}$

Brosig, Ockenfels and Weimann (forthcoming) compared a no communication baseline to several communication and other treatments. These included an FF treatment, an audio-visual conference, and a treatment with communication by an audio channel only. Their baseline, FF, and audio-visual treatments performed very much like our B, FF, and $\mathbf{C R}$ treatments, respectively. However, their audio-only treatment led to only slightly more cooperation than did their baseline. These results led them to conclude that "it does not make a difference if people talk face-to-face sitting at the same table or watching each other on a video screen. ... What is crucial ... is that there is face-to-face communication; in particular, audio communication (without face-to-face interaction) ... perform[s] significantly worse." They go on to speculate "that the particular success of face-to-face interaction has something to do with human evolution and socialization. During the evolution of human beings, face-to-face was the only available form of communication."

Our chat room finding seems inconsistent with Brosig et al.'s conclusions about face-to-face communication, but some caution is in order. Whereas Brosig et al. went to great lengths to isolate their subjects from one another in all treatments but FF, our subjects sat in the same room in every treatment, including CR. Although they could not tell who their partners were and they were not permitted to speak, signal or gesture physically to other subjects, they were visually aware of others' presence in the room. This awareness of proximity may have supplemented the written communications with

\footnotetext{
32 Rocco (1998) compared e-mail with face-to-face communication in a set of social dilemma experiments more akin in payoff structure to those of Ostrom et al. The significantly less successful cooperation achieved by e-mail groups in her experiment, as in Frolich and Oppenheimer's, may partly be due to the greater difficulty of her task, since it required identifying an interior equilibrium where investments in the group project are neither too low nor too high. In a comment comparing e-mail to FF but perhaps unintendedly shedding light on the inferiority of e-mail to a chat room, she noted that "In contrast to face-toface communication in which speakers govern the sequence of the discussion, in the mailing list sequence depends on the recipient of the messages who decides what to read first. The lack of need to take turns permits several threads to be discussed at the same time, causing the focus of the discussion to be lost." These problems may be less severe in a chat room, since all subjects automatically see the same messages appearing in the same order.
} 
evidence that "the others are real people like myself."33

Like contributions in the communication treatments, last period punishment in the reduction treatments suggests utility differing from material payoffs. Even though many of our subjects showed a strong propensity to punish free-riding, however, both contributions and earnings were considerably higher in the four treatments (FF, FFwR, CR, and

CRwR) with open ended communication than in those with punishment but without such communication. Adding a punishment option to a verbal communication treatment did not raise contributions significantly in one case (FF) and did so only modestly in the other (CR). Although the possibility of punishment appears to have deterred some free riding in the last period, most subjects shied away from explicit threats in their communications, preferring to cultivate a harmonious atmosphere of cooperation by agreement and not threat. The effectiveness of such agreements is probably the most impressive result to emerge from our analysis. $^{34}$

Theoretical discussions of the punishment problem, such as that by Henrich (forthcoming), have focused on the fact that while it benefits a group to have some "altruistic" punishers of free riding, the individual can earn a higher payoff by letting others provide the costly punishments. In our experiments, however, "second order free riding" may be less of a problem than is perverse punishment, the punishment of high contributors sometimes to avenge past punishment, sometimes to improve one's relative income, sometimes out of resentment or confusion. The informational structure of our own and similar experiments placed severe limits on subjects' information about what others were doing in the punishment stage. This may have made it difficult or impossible for norms of punishment to emerge or for "rogue" punishers to be disciplined by members

${ }^{33}$ Sally (1995) finds that physical isolation of subjects from one another significantly reduces contributions in VCM experiments.

${ }^{34}$ The difference between cooperation achieved by 'friendly' agreement and that brought about under the pressure of threats is remarkably illustrated by comparing the final period of the FF and CR treatments, discussed in this paper, with those of an "expulsion" experiment reported in Cinyabuguma, Page and Putterman (in progress). In the latter, subjects played a fifteen-round VCM game similar to that reported here in one large group of sixteen members, and had the power to expel individuals from the group (to a smaller group playing a VCM with lower endowments) by majority vote. In every experiment session, there were early expulsions, and subjects accordingly raised their contributions until they approached $100 \%$ of endowments, a level similar to those in the FF and $\mathbf{C R}$ treatments of this paper, in later periods. However, in the last period, when there is no further threat of expulsion, the average contribution precipitously fell, to about $30 \%$, in the expulsion treatment sessions. 
of their groups. Communication may have failed to improve the performance of punishment in our experiments because subjects lacked sufficient information for monitoring and punishing perverse punishment, and therefore failed to harness the potential benefits of inclinations to punish free riding.

In sum, communication of commitments permitted high efficiency levels to be achieved in our two verbal communication treatments. Observed reciprocity seemed to beget an atmosphere of cooperation that many did not want to unilaterally defect from. Without a vehicle for proclaiming commitments, numerical cheap talk lacked this effect. In treatments with reduction opportunities but without verbal communication, cooperation instilled by fear of punishment was lower on average, and more costly. Reductions were not limited to punishments of low contributors, but spilled over into retaliation and spite. In our experiments, perhaps, the non-pecuniary self-punishment of a guilty conscience proved more efficient than materially costly punishments imposed by others. 


\section{$\underline{\text { References }}$}

Andreoni, James and John H. Miller, 1993, "Rational Cooperation in the Finitely Repeated Prisoner's Dilemma: Experimental Evidence,” Economic Journal 103: 570-85.

Bergstrom, Theodore, 2002, "Evolution and Social Behavior: Individual and Group Selection," Journal of Economic Perspectives 16 (2): 67-88.

Bochet, Olivier and Louis Putterman, 2005, "Not Just Babble: Numerical Cheap Talk in a Public Goods Experiment" Brown University Department of Economics Working Paper 2005-05.

Brosig, Jeannette, 2002, "Identifying Cooperative Behavior: Some Experimental Results in a Prisoner's Dilemma Game," Journal of Economic Behavior and Organization 47: 275-90.

Brosig, Jeannette, Axel Ockenfels and Joachim Weimann, forthcoming, "Why Does Communication Enhance Cooperation?” German Economic Review (in press).

Carpenter, Jeffrey, 2000, "Mutual Monitoring in Teams: The Role of Monitoring Group Size, Second-Order Free-Riding, or Coordination," paper presented at a meeting of the Economic Science Association, New York, June.

Davis, Douglas D. and Charles A. Holt, 1993, Experimental Economics. Princeton: Princeton University Press.

Ertan, Arhan, Talbot Page and Louis Putterman, in progress, "Can Endogenously Chosen Institutions Mitigate the Free-Rider Problem and Reduce Perverse Punishment," Brown University Department of Economics.

Falk, Armin, Ernst Fehr and Urs Fischbacher, 2001, "Driving Forces of Informal Sanctions," Institute for Empirical Economics Working Paper No. 59, University of Zurich.

Fehr, Ernst and Simon Gächter, 2000a, "Cooperation and Punishment," American Economic Review

Fehr, Ernst and Simon Gächter, 2000b, "Fairness and Retaliation: The Economics of Reciprocity," Journal of Economic Perspectives 14 (3): 159-81.

Fehr, Ernst and Simon Gächter, 2002, "Altruistic Punishment in Humans," Nature 415: 137-40. 
Frank, Robert, 1988, Passions Within Reason: The Strategic Role of the Emotions. New York: W.W. Norton.

Frohlich, Norman and Joe Oppenheimer, 1998, "Some Consequences of e-mail vs. Face-to-Face Communication in Experiment," Journal of Economic Behavior and Organization 35 (3): 389-403.

Gächter, Simon and Ernst Fehr, 1999, "Collective Action as a Social Exchange," JEBO 39: 341-69.

Guttman, Joel, 2000, "On the Evolutionary Stability of Tastes for Reciprocity," European Journal of Political Economy 16 (1): 31-50.

Henrich, Joseph, "Cultural Group Selection, Coevolutionary Processes and LargeScale Cooperation, forthcoming, Journal of Economic Behavior and Organization.

Hoffman, Elizabeth, Kevin McCabe and Vernon Smith, 1996, "Social Distance and Other-Regarding Behavior in Dictator Games," American Economic Review 86: 65360.

Isaac, R. Mark and James M. Walker, 1988, "Communication and Free-Riding Behavior: The Voluntary Contributions Mechanism," Economic Inquiry 26: 585608.

Kreps, David, Paul Milgrom, John Roberts and Robert Wilson, 1982, "Rational Cooperation in Finitely Repeated Prisoners' Dilemma," Journal of Economic Theory 27: $245-52$.

Ledyard, John, 1995, "Public Goods: A Survey of Experimental Research,” pp. 11194 in John Kagel and Alvin Roth, eds., Handbook of Experimental Economics. Princeton: Princeton University Press.

McKelvey, Richard D. and Thomas R. Palfrey, 1992, “An Experimental Study of the Centipede Game," Econometrica 60 (4): 803-36.

Ostrom, Elinor, James Walker and Roy Gardner, 1992, "Covenants with and without a Sword: Self Governance is Possible." American Political Science Review. 86 (2): 404416.

Page, Talbot, Louis Putterman and Bulent Unel, 2002, "Voluntary Association in Public Goods Experiments: Reciprocity, Mimicry, and Efficiency," Brown University Dept. of Economics Working Paper 2002-19. [Final version appears in Economic Journal, 115: 1032-53, 2005.]

Rocco, Elena, 1998, "Trust Breaks Down in Electronic Contexts but Can Be Repaired by Some Initial Face-to-Face Contact," Proceedings of CHI (April): 496502. 
Saijo, Tatsuyoshi and Hideki Nakamura, 1995, "The 'Spite' Dilemma in Voluntary Contribution Mechanism Experiments," Journal of Conflict Resolution 38 (3): 53560.

Sally, David, 1995, "Conversation and Cooperation in Social Dilemmas: A MetaAnalysis of Experiments from 1958 to 1992," Rationality and Society 7 (1): 58-92.

Sefton, Martin, Robert Shupp and James Walker, 2002, "The Effect of Rewards and Sanctions in Provision of Public Goods," Working Paper, University of Nottingham and Indiana University.

Sen, Amartya, 1967, "Isolation, Assurance and the Social Rate of Discount," Quarterly Journal of Economics 81: 112-24. 


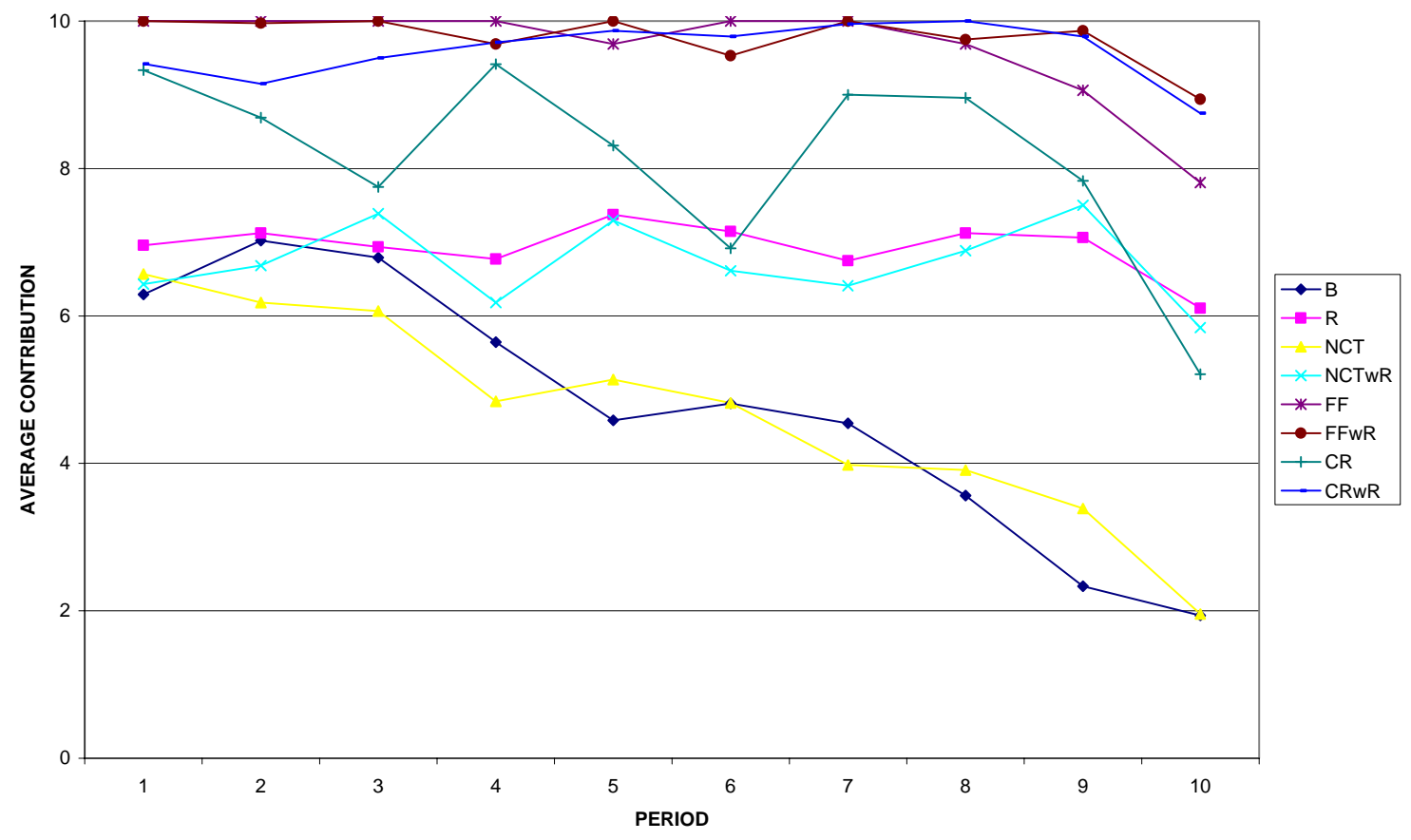

Figure 1

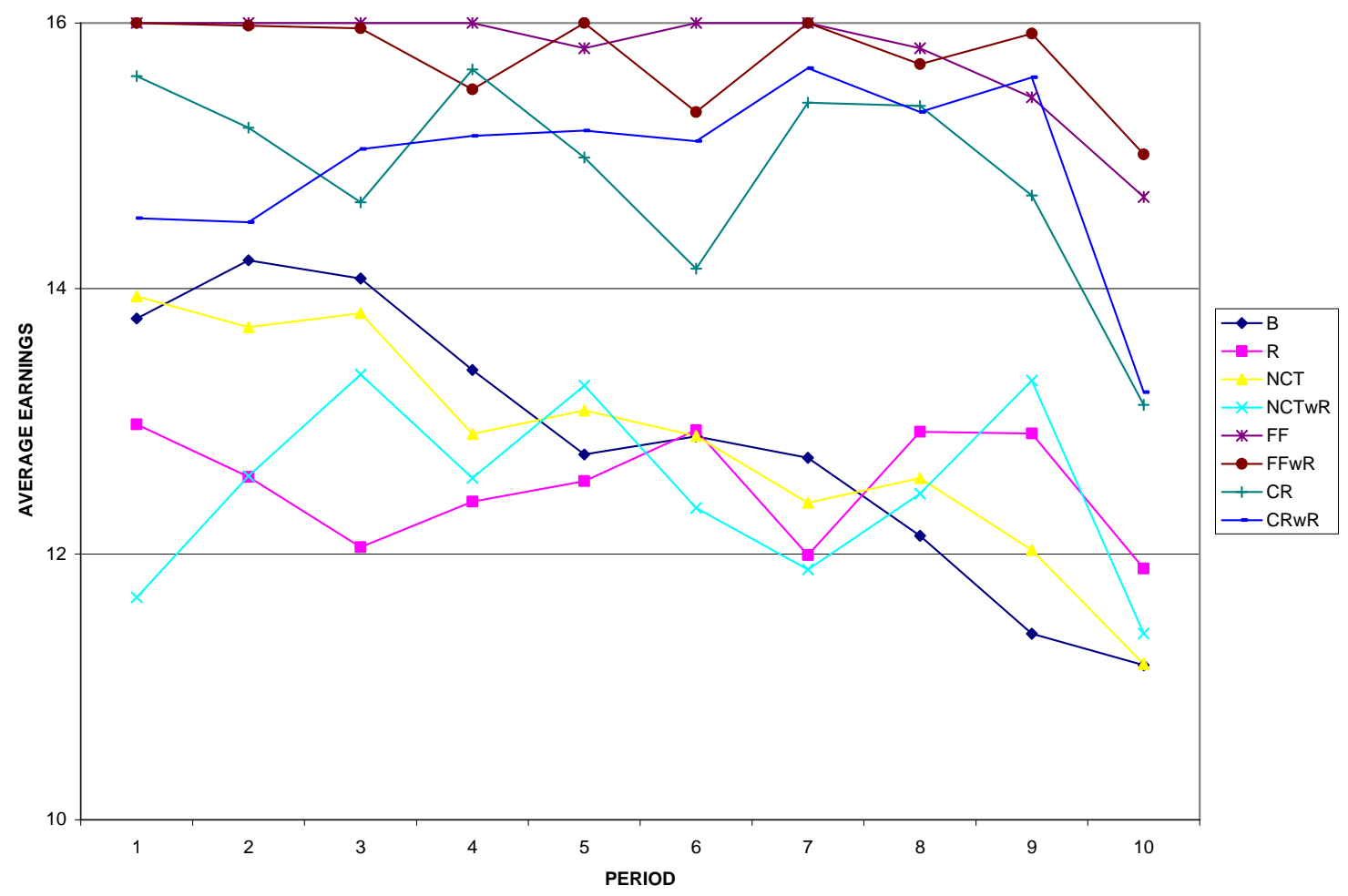

Figure 2 
Appendix A: Instructions ${ }^{34}$

[Screen 1]

This is an experiment, funded by a research foundation, to study decision making. You will be earn money in "experimental dollars" during the experiment. At the end of the experiment you will be paid in cash in real dollars (each experimental dollar is worth a real $\$ 0.13$, or thirteen cents). The amount you will earn will depend on your and others' decisions. The maximum possible earning is $\$ 50$ (real dollars) and the minimum possible is $\$ 8$. You are likely to earn an amount in between. Please make sure you understand the decision process.

[Screen 2]

\section{Your Group}

You will be placed in a group of four. The people in your group will not change during the experiment, but you will not know the identity of who is in your group, during the experiment or afterwards. The other three people in your group will have "screen names" of B, C, and D. Your screen name, on your screen, is A, but your screen name will be different on others' screens.

There will be 10 periods in the experiment. Although the real identity of each of the other people in your group is unknown to you, each screen name will refer to the same person during a period. (But at the end of each period the screen names will be randomly switched, and then fixed for the period.)

[Screen 3]

\section{Earnings}

Each period is like the others, so we will describe how your earnings for the first period are determined.

At the beginning of the period each person in your group will receive $\$ 10$ (experimental dollars). You must decide how to divide this amount between a group account and a personal account.

The money you assign to your personal account goes into your earnings.

An amount equal to 0.4 times the group's total assignment to the group account goes into your earnings.

$$
\text { Earnings }=(\text { amount in personal account })+(0.4)(\text { total in group account })
$$

[Screen 4]

34 These instructions are for the variant of the experiment with reduction option and numerical cheap talk. Instructions for variants without one or both of these elements are missing the screens that pertain to them. 
The next four screens are set up to help you test your understanding of the experiment. For each of the screens that follows, there is a paper worksheet on your desk. Fill in the blanks in the worksheet first, then enter the information in the practice decision screen. The numbers you type in the practice screens are for practice only and will net affect your earnings from the experiment.

Practice Questions

Practice 1.

Fill out the stage I section below for the following situation. The four members of your group each have $\$ 10$. Every member of your group has assigned $\$ 10$ to the group account and $\$ 0$ to their personal account.

1. Amount you assigned to group account:

2. Amount you assigned to your personal account: $\$$ (=\$10 - group account assignment on line 1)

3. Total number of dollars assigned to your group account:

4. Income from the group account for a member of you group: $\$$ $(0.4 \cdot$ group account total in line 3$)$

5. Your earnings after stage I: (group account income in line $4+$ personal account income in line 2)

Now, go back to the practice screen. Type in your contribution in the window and submit it to make sure your calculations are correct.

Practice 2.

Fill out the stage I section below for the following situation. The four members of your group each have $\$ 10$. Every member of your group has assigned $\$ 0$ to the group account and $\$ 10$ to their personal account.

1. Amount you assigned to group account:

2. Amount you assigned to your personal account:

$\$$

$\$$ (=\$10 - group account assignment on line 1)

3. Total number of dollars assigned to your group account:

$\$$

4. Income from the group account for a member of you group: $\$$ $(0.4 \cdot$ group account total in line 3$)$

5. Your earnings after stage I:

(group account income in line $4+$ personal account income in line 2)

Now, go back to the practice screen. Type in your contribution in the window and submit it to make sure your calculations are correct. 
Practice 3.

Person 2 assigned $\$ 10$ to the group account and $\$ 0$ to his personal account, person 3 assigned $\$ 5$ to the group account and $\$ 5$ to his personal account and person 4 assigned $\$ 0$ to the group account and $\$ 10$ to his personal account.

Fill out the stage I section bellow for the above situation where you assigned $\$ 5$ to the group account.

1. Amount you assigned to group account: $\$$

2. Amount you assigned to your personal account: $\$$ $(=\$ 10-$ group account assignment on line 1$)$

3. Total number of dollars assigned to your group account: $\$$

4. Income from the group account for a member of you group: $\$$ $(0.4 \cdot$ group account total in line 3$)$

5. Your earnings after stage I:

(group account income in line $4+$ personal account income in line 2)

Now, go back to the practice screen. Type in your contribution in the window and submit it to make sure your calculations are correct.

Practice 4.

Person 2 assigned $\$ 10$ to the group account and $\$ 0$ to his personal account, person 3 assigned $\$ 5$ to the group account and $\$ 5$ to his personal account and person 4 assigned $\$ 0$ to the group account and $\$ 10$ to his personal account.

Fill out the stage I section bellow for the above situation where you assigned $\$ 6$ to the group account.

1. Amount you assigned to group account:

2. Amount you assigned to your personal account:

$\$$ $(=\$ 10-$ group account assignment on line 1$)$

3. Total number of dollars assigned to your group account:

4. Income from the group account for a member of you group: $\$$ $(0.4 \cdot$ group account total in line 3$)$

5. Your earnings after stage I:

(group account income in line $4+$ personal account income in line 2)

How does this change affect the earnings of other members of your group, assuming that the switch of $\$ 1$ from your individual to your group account is the only change? 
Now, go back to the practice screen. Type in your contribution in the window and submit it to make sure your calculations are correct.

[Screen 8]

\section{Reductions}

There is another decision that affects your earnings. Once you learn the others' assignments to the group account, you have a chance to reduce others' earnings, and others have a chance to reduce your earnings. Suppose, in the last example, you decide to reduce B's earnings by $\$ 3$, C's earnings by $\$ 5$, and D's earnings by $\$ 0$. The total amount of reductions you make on others' earnings is $\$ 8$.

It costs you $\$ 0.25$ for each $\$ 1$ you reduce others' earnings. So your own earnings are reduced by $(0.25)(\$ 8)=\$ 2$ in this example.

Just as you can reduce others' earnings, others can reduce yours. Suppose B reduces your earnings by $\$ 1, \mathrm{C}$ by $\$ 3$ and $\mathrm{D}$ by $\$ 5$. The total reduction of your earnings by others is $(\$ 1+\$ 3+\$ 5)=\$ 9$. You will learn that your earnings have been reduced by a total of $\$ 9$ but you will not learn who has reduced your earnings by what amount.

Similarly none of the others will learn by how much you have reduced their earnings, but only the total reductions.

Please fill in the sheet labeled practice 5 and the corresponding practice decision screen.

\section{Practice 5.}

It costs you $\$ 0.25$ to reduce the income of another person by $\$ 1.00$. Fill out the stage II section bellow for the following situation:

You assigned $\$ 5$ to the group account and $\$ 5$ to your personal account, person 2 assigned $\$ 10$ to the group account and $\$ 0$ to his personal account, person 3 assigned $\$ 5$ to the group account and $\$ 5$ to his personal account and person 4 assigned $\$ 0$ to the group account and $\$ 10$ to his personal account. You reduce person 2's earnings by $\$ 2$, person 3's by $\$ 3$ and person 4's by $\$ 4$. You receive a total of $\$ 1$ in reductions from other members of your group.

1. Amount you assigned to group account:

2. Amount you assigned to your personal account: $(=\$ 10-$ group account assignment on line 1$)$ 
3. Total number of dollars assigned to your group account:

4. Income from the group account for a member of you group: $\$$ $(0.4 \cdot$ group account total in line 3$)$

5. Your income after stage I:

(group account income in line $4+$ personal account income in line 2)

6. You reduced the earnings of others in vour groun bv a total of: $\$$

7. This cost you:

$\$$

$(0.25 *$ the sum of your reductions from line 6$)$

8 . Other members of your group reduced your earnings by:

9 . The total change in your income from stage 2: (line $7+$ line 8)

10. Your total income for these two stages: $\$$

Now, go back to the practice screen. Enter and submit your reductions to make sure your calculations are correct.

[Screen 9]

$$
\text { Your Net Earnings }
$$

Your net earnings for a period will be:

Amount in personal account +

$(0.4)$ (Total in group account) -

$(0.25)$ (Total of your reductions of others) -

Total of reductions of your earnings made by others.

At the end of the experiment, the net earnings for the 10 periods will be totaled and converted from experimental dollars to real dollars. Then $\$ 5$ will be added for your participation.

[Screen 10]

\section{Process}

At the beginning of each period there will be a communication stage. You will type in a possible amount for your group assignment. To do this you click on the red highlighted box, type in a whole number from 0 to 10, and press ENTER.

When others have typed in their possible amounts to the group assignment, you type in your possible reductions of others' earning. To do this, click on each of the blue highlighted boxes, type in a whole number, and press ENTER. At any time during this stage, you can adjust your possible assignment to the group account and your possible reductions, by clicking on a red or blue box, backspacing out the current number, typing in a new number, and pressing ENTER. 
A clock will show you how much time you have for the communication stage. In the earlier periods you will have more time. In the later periods this stage will be shortened.

You are not committed to any of the numbers you type in during this stage.

Once the time ends for this stage, there is a decision commitment stage. First you type in your real and final choic e for your assignment to the group account. When everyone in your group has done so, you type in your real and final choices for your reductions of others.

The net earnings for the period will be shown on the bottom box.

Any questions?

Appendix B. Additional Instructions for Face-to-Face Communication Treatments

Discussion Period

Once the decision phase of the experiment begins, you will be asked to remain at your seat and to refrain from any form of communication with other participants, except by the entry of your decisions on the decision screens. After the completion of these instructions, however, you will be brought together with the other members of your group and will have an opportunity to talk with them for five minutes. During that time, you can discuss anything you like with one exception: promises of rewards or threats of punishment to occur after the experiment are not permissible.

Appendix C. Additional Instructions for Chat Room Treatments

[Screen 6] 


\section{Communication}

At three points during the experiment, you will have the opportunity to communicate with the other members of your group. During these communication periods, which will take place just before round 1 , round 4, and round 7, you and other members of your group are invited to use your keyboards to type messages to one another. At the beginning of each communication period, you will learn which letter, A, B, C or D, has been assigned to you for that period. When you type a message to your group, your identification letter will appear before the message. This letter will remain fixed during the course of a given communication period and the immediately following decision stage.

During a communication period, you can indicate in the text of a message that that message is intended primarily for a particular group member, for instance by typing "I agree withyou, D." However, any message sent to your fellow group members will appear on the screens of all members of your group (but not on those of members of other groups).

[Screen 7]

\section{Communication Rules}

During a communication period, you can discuss anything you like, including what you think is the best approach to the experiment, what you plan to do, or what you would like others to do.

However, there are two restrictions on the types of messages that you may send.

First, you may not send a message that attempts to identify you to other group members other than by your letter A, B, etc. Thus, you may not use your real name, nicknames, or selfdescriptions of any kind ("Tom Smith here," "I'm the guy in the red shirt sitting near the window," "It's me, Sandy, from French class," or even "As a woman [Latino, AsianAmerican, etc.], I think..."). To make sure that the rule of anonymity is adhered to, each message will be screened by a monitor who is a member of the experiment team before it is seen by the other members of your group.

The second restriction is that there must be no threats or promises pertaining to anything that is to occur after the experiment ends.

If a message is found to violate either rule, it will not go to the other members of your group, and you will receive a message from the monitor informing you of this fact.

A clock will show you how much time you have left in the communication period.

[Screen 8]

When a communication period ends, it is followed immediately by a decision period in which you and the other members of your group enter the amounts you are assigning to the group account, in the manner seen in the examples. These are binding decisions that affect your earnings from the experiment.

During the decision period that immediately follows a communication period, you and the other members of your group will be identified by the same letters A, B, C and D which you 
were assigned for the communication period. Those particular letter assignments will end, however, at the end of the first decision period following communication. In the next decision period, and in later communication periods, new random letters will be assigned. In a period that does not include communication, you will be identified to yourself simply as "You."

\section{[Screen 9]}

This completes the instructions for the experiment. You will now have a chance to ask any questions you have in order to clarify how the experiment will work. It is important to note that once the question period ends and the experiment begins, there is to be no further communication apart from what takes place through your terminals. 
End of Binding Decision Stage

$$
\begin{aligned}
& \text { Itis is rand J or } 10 \\
& \text { Time Expied. Please }
\end{aligned}
$$

Tire Exoired. Please make your decisien now

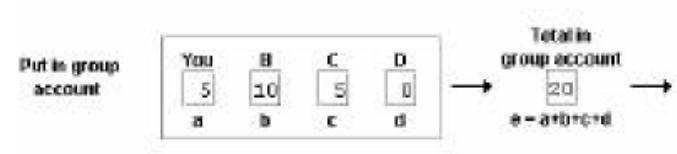

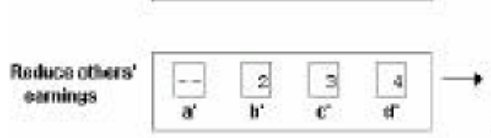

Thes a aib he results for fourd 3.

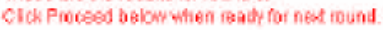

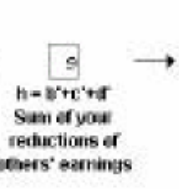

eners' earings

Proceed

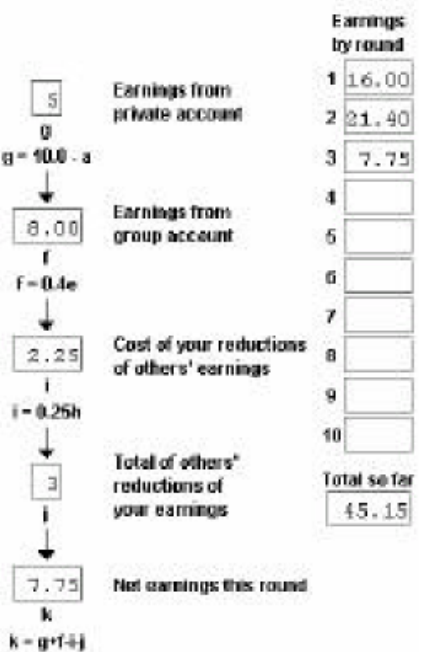

$\frac{7.75}{6}$ Mes aanings the rount

$k=g+i+4$ 